\title{
Retrospective Analysis of the Patients Treated in the Emergency Intensive Care Unit of a University Hospital for a Year
}

\author{
Ertan Sönmez, Ali Dur, Bedia Gülen, Kenan Ahmet Türkdoğan, Cemil Civelek, Özgür Söğüt, Mehmet Yiğit, Abuzer Özkan \\ Department of Emergency Medicine, Bezmialem Vakıf University Faculty of Medicine, İstanbul, Turkey
}

\begin{abstract}
Aim: Failure in hospitalization of intensive care unit (ICU) patients, directly affect the emergency department processing and the clinics of the patients negatively. In this retrospective study, we analyzed patients admitted to the emergency department ICUs.
\end{abstract}

Materials and Methods: In this study, a total of 388 patients who were treated in an emergency ICU of a university hospital for a year were screened retrospectively. The duration of hospitalization and outcomes were compared with those of patients treated in the other ICUs of the hospital. The effect of emergency ICU on the number of patients sent to another hospital because of the lack of empty beds in the ICU and mortality were evaluated.

Results: The ratio of the patients treated in the emergency ICU constituted $19.2 \%$ of the patients hospitalized in all ICUs of our hospital ( $n=2108$ ). The number of patients who were admitted to the ICU of another hospital because of the lack of empty beds was 374. The duration of emergency ICU stay was too long (489.49 minute). The shortest duration of stay was observed in patients admitted to the coronary and neurology ICUs ( 267.36 and 349.36 minute, respectively).

Conclusion: Our study revealed that emergency ICUs significantly reduces the number of referrals to the ICUs of another hospital and the duration of the emergency service follow-up period. (Eurasian J Emerg Med 2015; 14: 134-7)

Keywords: Intensive care, emergency, density in the emergency service

\section{Introduction}

With the increase in elderly population, the need for intensive care units (ICUs) is gradually increasing in our country and in the world. Admission to ICUs should be made by considering the severity of the medical condition and the necessity to support vital functions (1). Determination of this requisite is very difficult in some hospitals where the number of admissions is excessive, and many of the patients requiring intensive care cannot be hospitalized because of the lack of an empty bed. Based on their institutional goals and treatment modalities, ICUs in hospitals are divided into three groups such as first-, second-, and third-level ICUs (2-4). First-level ICUs provide intensive nursing service. Second-level ICUs provide a specialist doctor who is responsible for that ICU and ready to be called. Nursing care is also more intense. Third-level ICUs offer trained health personnel with full-time laboratory and radiology services. The devices and equipments specifically designed for ICUs are used. Consultations can be held when there is a need $(3,4)$. Before being a university, our hospital was a support hospital. Because of this prevalent feature and its central location, emergency room visits are excessive; therefore, there was a need for an ICU. Because our hospital fails to satisfy the demand for an ICU, many of the patients are referred to other hospitals. Difficulty in referrals and patients' needs for adequate treatment and care have created the need for establishing a first-level ICU in the emergency department. In this study, we retrospectively analyzed the patients who were treated in the first-level emergency ICU of the Bezmialem Vakif University Medical School for a year.

\section{Materials and Methods}

After obtaining approval from the Ethics Committee of the Bezmialem Vakif University, transcriptions of the patients admitted to the emergency department between 05.01.2012 and 05.01.2013 were retrospectively screened via the BizMed patient data recording program. Because of the retrospective nature of this study, informed consent was waived. All patients (age $>16$ years) requiring admission to an ICU and all the traumatic patients were enrolled in the study. The following patients were excluded from the study: those who died

Correspondence to: Ertan Sönmez e-mail: ertansonmez3@msn.com

Received: 13.02.2015 Accepted: 21.04.2015

(C) Copyright 2015 by Emergency Physicians Association of Turkey - Available online at www.eajem.com

DOI: 10.5152/eajem.2015.35467 
before hospital admission and those were alive after cardiopulmonary resuscitation but rearrested before being admitted to the ICU, patients (age $<16$ years) admitted to the ICU because of non-traumatic diseases, patients transferred from the ICUs of other hospitals, and those transferred to ICUs after the admission to the clinic from the emergency department. Demographic data such as age; gender; the date of admission; the number of patients hospitalized in the anesthesia, postoperative, coronary, cardiovascular surgery, neurology, and emergency ICUs; duration of hospitalization; and patients outcomes (transfer to service, transfer from ICUs, discharge, died, transfer to another hospital ICU) were examined.

\section{Statistical analysis}

The data were analyzed using the Statistical Package for Social Sciences 15.0 (SPSS, Chicago, IL, USA). Frequency distribution and percentages were used for data analysis.

\section{Results}

The mean number of patients admitted to the emergency department was 924 per day (332,640 per year). Of these, 2018 (0.60\%) patients were admitted to the ICUs from the emergency department. A total of 374 patients, which constituted one fifth of all the patients hospitalized in ICUs, were referred to the ICUs of other hospitals because of various reasons or lack of an empty bed. Of the patients admitted to the ICUs, 953 (47.2\%) were female and 1065 (52.8\%) were male. Of these patients, $388(19.2 \%)$ received treatment in emergency, 682 (33.8\%) anesthesia, 91 (4.5\%) postoperative, 158 (7.8\%), neurology, $296(14.7 \%)$ coronary, 359 (17.8\%) chest, 41 (2\%) pediatric, and $3(0.1 \%)$ cardiovascular ICUs. Approximately $3 \%$ of the patients $(n=60)$ was referred to the ICUs of other hospitals (Figure 1). While the length of intensive care stay was less than $6 \mathrm{~h}$ for coronary and neurology patients, this was longer than $6 \mathrm{~h}$ for emergency and other ICUs (Figure 2). The average duration of stay for patients shifted from an emergency service to any ICU was $419.17 \mathrm{~min}$, whereas it was

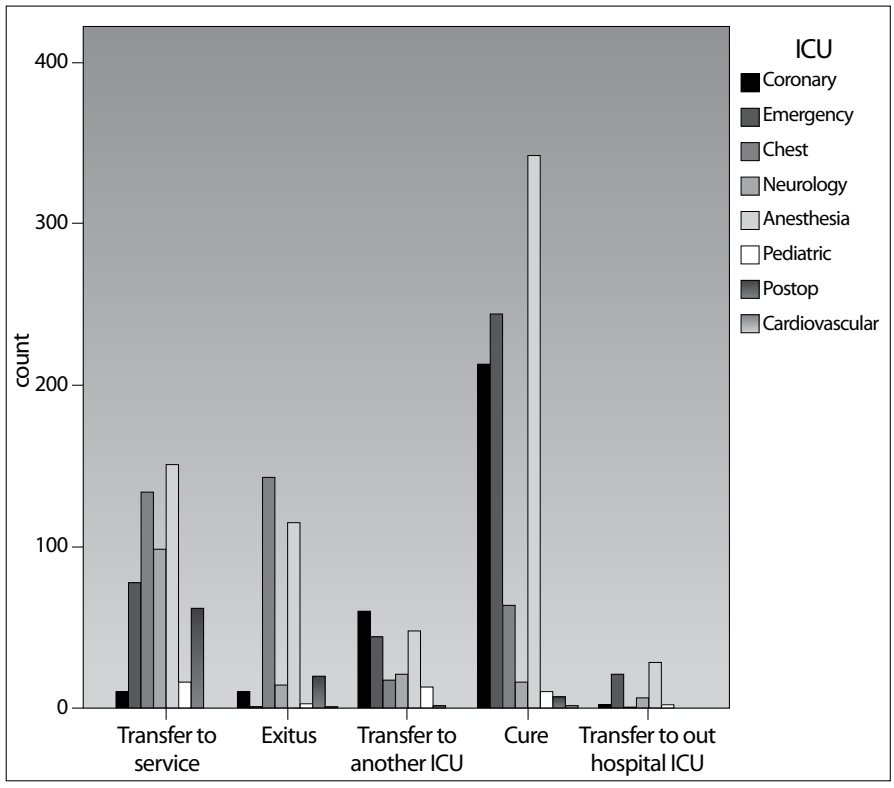

Figure 1. Distribution of the patients admitted to the ICU with respect to the patient outcomes ICU: intensive care unit
489.49 min for patients admitted to an emergency ICU. The mean duration of ICU stay was $267.36 \mathrm{~min}$ and $349.36 \mathrm{~min}$ in the cardiology and neurology ICUs. This duration was $489.49 \mathrm{~min}$ in an emergency ICU. The mean duration of stay in the pediatric ICU was $186.60 \mathrm{~min}$ (Table 1). The most common patient outcomes in the emergency ICU was healing/discharge from the hospital (244 patients; 62.9\%). Only one patient $(0.3 \%)$ died. Mortality was most frequent in the chest (143 patients; $46.6 \%)$ and anesthesia $(114 ; 37.1 \%)$ ICUs. Patient transferring to other services was most frequent in the anesthesia ICUs (151 patients; $27.6 \%$ ) (Figure 1). Sixty patients were referred to the ICUs of other hospitals during their treatments. While 130 of 307 discharged patients were admitted to the ICU before $6 \mathrm{~h}$, the remaining 177 patients stayed in the ICU for more than $6 \mathrm{~h}$.

\section{Discussion}

Healthcare resource distribution refers to mean resources among individuals and populations and encompasses rationing and

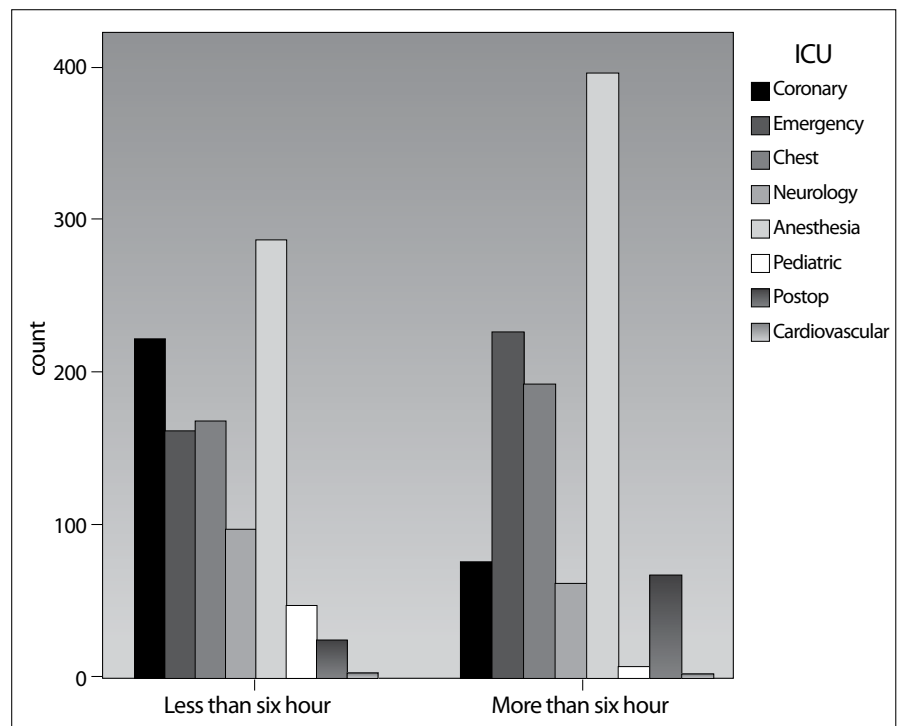

Figure 2. Distribution of duration of stay of the patients admitted to any ICU from an emergency department before and after $6 \mathrm{~h}$ ICU: intensive care unit

Table 1. The mean durations from the emergency department to admission to the ICU

\begin{tabular}{|l|c|c|c|}
\hline ICU & Mean time (min) & $\mathbf{n}$ & SD \\
\hline Coronary & 267.36 & 296 & 285.930 \\
\hline Emergency & 489.49 & 388 & 361.228 \\
\hline Chest & 417.27 & 359 & 427.091 \\
\hline Neurology & 349.36 & 158 & 356.133 \\
\hline Anesthesia & 459.24 & 682 & 391.279 \\
\hline Pediatric & 186.60 & 41 & 353.231 \\
\hline Postop & 541.92 & 91 & 396.054 \\
\hline Cardiovascular & 550.12 & 3 & 332.275 \\
\hline Total & 419.17 & 2018 & 384.160 \\
\hline ICU: intensive care unit; SD: standard deviation; min: minute \\
\hline
\end{tabular}


triage. There is a substantial need for all medical services with more complex medical procedures because of increasing patient age and expectations and an increased severity of diseases. For all these conditions, sometimes there is a need for continuous monitoring. Frequently, when it comes to ICUs, the need exceeds the supply, leading to a rationing of ICU beds. As a result, a method of triaging is needed, often resulting in admission refusal (5-9).

Based on their organizational goals and treatment modalities, ICUs in hospitals are divided into three groups such as first-, second-, and third-level ICUs. First-level ICUs provide intensive nursing service. They are the ICUs where monitoring [electrocardiogram (ECG), heart rate, and $\mathrm{SaO}_{2}$ ] and resuscitation are performed and, when needed, respiratory support can be given up to $24 \mathrm{~h}$. Physician service mostly involves consultation (2-4). Second-level ICUs provide a specialist doctor who is responsible for that ICU and ready to be called when needed. Nursing care is much more intensive. Long-term respiratory support, cardiac monitoring, nutrition, and preventive physical therapy and rehabilitation services are offered. Some invasive diagnostic and therapeutic procedures such as hemofiltration, intracranial pressure measuring, and pulmonary artery catheterization can be applied (2-4). Third-level ICUs offer trained health personnel with full-time laboratory and radiology services. The devices and equipments specifically designed for ICUs are used. Consultations can be held when they are necessary $(3,4)$. Before being a university, our hospital was a support hospital. Because of this prevalent feature and its central location, emergency room visits are excessive; thus, there was a demand for ICUs. Because our hospital fails to satisfy the demand for intensive care, many of the patients are referred to other hospitals. Difficulty in referrals and patients' needs for adequate treatment and care have created the need for establishing a first-level ICU in the emergency department. In this study, we retrospectively analyzed the patients who were treated in the first-level emergency ICU of Bezmialem Vakif University Medical School for a year.

The patients admitted to the emergency ICU included patients requiring first-level intensive care. In addition to first-level intensive care, an emergency medicine physician assistant constantly followed up the patients. On the other hand, another one followed up the patients with regular visits. These patients consisted of those who could not be admitted because of a lack of an empty bed in our ICU and those who were referred to our hospitals from other healthcare organizations because of various reasons. The need for first-level emergency ICUs has arisen from the lack of empty beds in an ICU, which leads to a long-term follow-up and treatment in the emergency department. Therefore, the medical condition of seriously ill patients can further worsen, which leads to an increase in the density of emergency service.

In a prospective study investigating the duration of ICU stay and labor intensity in the emergency department, Fromm et al. (10) showed that these patients significantly increase the labor intensity of emergency services. In their study, Chalfie et al. (11) showed that delays in admission to emergency services negatively affect the duration of hospital stay and mortality. Patient outcomes heavily depend on the timely intervention for critically ill patients (12-18). Thus, prolonged ICU admission time may be an important factor affecting the patient outcomes. However, the effect of this delay cannot be fully estimated. There are three factors affecting the admission of critically ill patients from the emergency department: 1) increased number of critically ill patients admitted to the emergency department,
2) excessive density of patients in the hospital and emergency department, and 3) lack of an empty intensive care bed (2-4). Lambe et al. (19) showed a $59 \%$ increase in the number of critically ill patients admitted to the California emergency department between 1990 and 1999. In a study conducted in 2002 by the American Hospital Association (AHA), the mean duration of stay of the patients admitted to ICUs from emergency departments was $5.8 \mathrm{~h}$ in large hospitals having labor intensity in the emergency departments. In those with uncrowded emergency departments, this value was less than half (2). In our study, the mean duration of stay of the patients admitted to the ICU from the emergency department was $419 \mathrm{~min}$; this result was consistent with those of large hospitals having overcrowded emergency departments. In Fromm et al.'s (10) study of 17,900 emergency department admissions, the ratio of ICU patients was found to be $8.5 \%(n=1,527)$. The mean duration of stay in the emergency room was $145.3 \mathrm{~min}$. They showed that this group of patients is an important factor in increasing the labor intensity in the emergency services. Varon et al. (20) found that the mean length of stay in the emergency department was 284.5 min for ICU patients. Chalfin et al. (11) investigated more than 50,000 patients admitted to the emergency service for 4 years. They showed that mortality was higher and the length of hospital stay was longer in patients who stayed for more than $6 \mathrm{~h}$ in the emergency service. Having a low ICU hospitalization rate $(0.60 \%)$ among 332,640 patients can be attributed to the excessive number of admissions and outpatients. A longer duration of stay in the emergency department (an average of $419 \mathrm{~min}$ ) for all ICU patients can be attributed to the density in the emergency service. A longer duration of stay in the emergency ICU in our study (an average of $489 \mathrm{~min}$ ) can be explained by the fact that these patients had multidisciplinary diagnosis rather than a specific one. In our study, 130 of 307 discharged patients were admitted to the ICU before $6 \mathrm{~h}$, whereas the remaining 177 stayed for more than $6 \mathrm{~h}$ in the ICU. A longer duration of stay was associated with the excessive mortality. These findings suggest that care and treatment of the patients waiting for admission in the emergency departments for a long time are inadequate. In response to the delays in care and these concerns, the Robert Wood Johnson Foundation invested millions of dollars to reduce the density in the emergency department (21). In Medical Institute's report on "The Future of Emergency Service in United Nations," emergency hospitalization was considered to be the major concern that endangers the health of people (22).

Findlay et al. (23) investigated 774 patients who were admitted to the ICU between January 1993 and December 1994 and found that the length of ICU stay ranged from 1 to 68 days, and the median duration of ICU stay was 2 days. In their study of 967 patients, Özkan and Şahinoğlu (15) found the total duration of hospital stay to be 7500 days (median 4 days). The duration of hospital stay ranged from 1 to 77 days. In their study of neurosurgery ICU, Kurucu et al. (24) found that the duration of ICU stay of postoperative patients ranged from 1 to 34 days. The total duration of 36 patients was 155 days (mean 4.3 days). Considering the patient outcomes, 31 patients $(86.1 \%)$ were taken to the service and five patients (13.9\%) were transferred to other clinics. In our study, the mean duration of stay was 6.20 days (ranging from 1 day to 69 days). This value was 3.19 days in the emergency ICU (below the average but consistent with the literature). The total duration of stay of 91 patients in postoperative ICU ranged from 1 to 69 days (mean 7.32 days). Sixty-two patients (68.1\%) were taken to the services and 20 patients (22\%) died. 
In their study, Özkan and Şahinoğlu (15) found that 444 of 967 patients died and ICU mortality was $46 \%$. The mortality rate was found to be $0.5 \%$ in a study of 567 poisoning cases treated in the emergency department of a university hospital for 4 years (25). In our study, mortality was most frequent in the chest ICU (143 patients, $46.6 \%)$. The number of discharge patients in the emergency ICU was only one $(0.3 \%)$. Although this is a specific patient group study, the rate for emergency service shows similarities with the 4-year study. The low mortality rate can be explained by two reasons: first, the patients were first-level ICU patients and second, those whose medical conditions deteriorated were sent to other intra and/or inter-hospital ICUs [44 patients (11.3\%) and 21 patients (5.4\%), respectively].

In 1-year period of time, a total of 2018 patients were admitted to our ICU. On the other hand, 374 patients were sent to other hospitals because of a lack of empty beds or various reasons. In addition, 60 patients were referred to the ICUs of other hospitals during their treatments. If an emergency ICU was not available, 388 patients treated in the emergency ICU would have been sent to other hospitals, which could yield an extra burden.

\section{Study limitations}

The patients transferred to the ICUs of other hospital were treated by them. Therefore, the data of those patients could not be included in the study.

\section{Conclusion}

Emergency ICUs are the facilities where a great majority of the first-level patients are treated. In addition to its low mortality, it reduces the patients' referrals to the ICUs of other hospitals and provides adequate follow-up in the emergency department. It becomes an important alternative for intensive care patients in hospitals having a crowded emergency service.

Ethics Committee Approval: Ethics committee approval was received for this study from the ethics committee of Bezmialem Vakif University (71306642050.01.04).

Informed Consent: Due to the retrospective nature of this study, informed consent was waived.

Peer-review: Externally peer-reviewed.

Conflict of Interest: The authors declared no conflict of interest.

Financial Disclosure: The authors declared that this study has received no financial support.

\section{References}

1. Guidelines for intensive care unit admission, discharge, and triage. Task Force of the American College of Critical Care Medicine, Society of Critical Care Medicine. Crit Care Med 1999; 27: 633-8. [CrossRef]

2. Teoh LS, Gowardman JR, Larsen PD, Green R, Galletly DC. Glasgow Coma Scale: Variation in mortality among permutations of specific total scores. Intensive Care Med 2000; 26: 157-61. [CrossRef]

3. Krespi Y, Altındağ E. Nörolojide acil yaklaşımlar. Available at: http://www. itfnoroloji.org/acil/acil.htm. Access date: 29.01.2015

4. Zarén B, Bergström R. Survival of intensive care patients. I: Prognostic factors from the patient's medical history. Acta Anaesthesiol Scand 1988; 32: 93-100. [CrossRef]
5. Sprung CL, Geber D, Eidelman LA, Baras M, Pizov R, Nimrod A, et al. Evaluation of triage decisions for intensive care admission. Crit Care Med 1999; 27: 1073-9. [CrossRef]

6. Walter KL, Siegler M, Hall JB. How decisions are made to admit patients to medical intensive care units (MICUs): a survey of MICU directors at academic medical centers across the United States. Crit Care Med 2008; 36 : 414-20. [CrossRef]

7. Joynt GM, Gomersall CD, Tan P, Lee A, Cheng CA, Wong EL. Prospective evaluation of patients refused admission to an intensive care unit: triage, futility and outcome. Intensive Care Med 2001; 27: 1459-65. [CrossRef]

8. Sinuff T, Kahnamoui K, Cook DJ, Luce JM, Levy MM. Rationing critical care beds: a systematic review. Crit Care Med 2004; 32: 1588-97. [CrossRef]

9. Fan E, Needham DM. Deciding who to admit to a critical care unit. BMJ 2007; 335: 1103-4. [CrossRef]

10. Fromm RE Jr, Gibbs LR, McCallum WG, Niziol C, Babcock JC, Gueler AC, et al. Critical care in the emergency department: a time-based study. RL Crit Care Med 1993; 21: 970-6. [CrossRef]

11. Chalfin DB, Trzeciak S, Likourezos A, Baumann BM, Dellinger RP; DELAY-ED study group. Impact of delayed transfer of critically ill patients from the emergency department to the intensive care unit. Crit Care Med 2007; 35: 1477-83. [CrossRef]

12. Esener Z. Klinik anestezi. 2nd ed. İstanbul: Logos Yayıncılık Tic. AŞ; 1997: 696-9.

13. Şahinoğlu H. Yoğun bakım sorunları ve tedavileri. 1 th ed. Ankara: Türkiye Klinikleri Yayınevi; 1992: 3-8.

14. Uysal N, Gündoğdu N, Börekçi Ş, Dikensoy Ö, Bayram N, Uyar M, ve ark. Üçüncü basamak merkezde dahili yoğun bakim hastalarinin prognozu. Yoğun Bakım Derg 2010; 1: 1-5.

15. Özkan F, Şahinoğlu H. Ondokuz Mayıs Üniversitesi Tıp Fakültesi Cerrahi Yoğun Bakım Ünitesinde yatan 967 hastanın retrospektif analizi. Deneysel ve Klinik Tıp Dergisi 2009; 26: 62-7. [CrossRef]

16. Staudinger T, Stoiser B, Müllner M, Locker GJ, Laczika K, Knapp S, et al. Outcome and prognostic factors in critically ill cancer patients admiddet to the intensive care unit. Crit Care Med 2000; 28: 1322-8. [CrossRef]

17. Dur A, Cander B, Koçak S, Girişgin S, Gül M, Koyuncu F. Travmada skorlama sistemleri. Eurasian J Emerg Med 2009; 8: 4.

18. Mpe MJ, Mathekga K, Mzileni MO. The outcome of neuro-trauma. A 1 year retrospective study in an intensive care unit. Critical Care 2001; 5 115-9. [CrossRef]

19. Lambe S, Washington DL, Fink A, Herbst $\mathrm{K}$, Liu H, Fosse J, et al. Trends in the use and capacity of California's emergency departments, 1990-1999. Ann Emerg Med 2002; 39: 389-96. [CrossRef]

20. Varon J, Fromm RE Jr, Levine RL. Emergency department procedures and length of stay for critically ill medical patients. Ann Emerg Med 1994; 23: 546-9. [CrossRef]

21. Siegel B. Perspectives: It's Time to Share Tools to Mend the Safety. Available at: https://smhs.gwu.edu/urgentmatters/news. Access date: 04.09.2015

22. The future of emergency care in the United States health care system: Institute of Medicine, June 2006. Available at: http://www.iom.edu. Accessed June 26, 2006.

23. Findlay JY, Plenderleith JL, Schroeder DR. Influence of social deprivation on intensive care outcome. Intensive Care Med 2000; 26: 929-33. [CrossRef]

24. Kurucu NM, Efil S, Eser O, Aslan A, Karabekir HS. Retrospective analysis of hospitalized patients in neurosurgery intensive care unit. Balıkesir Saglık Bil Derg 2013; 2: 2. [CrossRef]

25. Sonmez E, Karakus A, Cavus UY, Civelek C, Ipek G, Zeren C. Evaluation of intoxication cases admitted to the emergency department of a university hospital. Dicle Med J 2012; 39: 21-6. [CrossRef] 